\title{
THE SNOWY RIVER PROJECT (S.E. AUSTRALIA)
}

3816

\author{
By Prof. S. E. WADHAM \\ University of Melbourne
}

\author{
and
}

PROF. D. M. MYERS
University of Sydney

PROF. D. M. MYERS
University of Sydney
YRRIGATION in Australia, which began in the 1 'seventies and staggered uneasily for half a century, during which it learned its lessons and found the appropriate techniques, has come into its own in the last two decades. Its extension is regarded as an essential feature in national development. Most parts of the continent lack permanent streams; but among the ranges which run parallel to the eastern coastline are several areas high enough and wide enough to form catchments yielding large volumes of water. Some are snow-clad for several months, and thus have a run-off which tends to have a better distribution than others. Among these, the plexus of ranges and tablelands in the Mt. Kosciusko region. of the south-east is the outstanding example. This area contains the Murray catchment and those of its tributaries, the Murrumbidgee and the Tumut, and of the Snowy. The Murray has a system of storages and locks developed during the last forty years, while the Murrumbidgee has the Burrinjuck storage and several locks. The Hume reservoir on the Murray holds $1,250,000$ acre feet, and will be extended to hold 2,000,000 acre feet. Burrinjuck holds 662,000 acre feet for irrigation. The Snowy, with an average yearly flow on the tableland of 970,000 acre feet, remains as the largest stream in the region available for future development. It rises under Mt. Kosciusko, and after flowing north, turns southward and falls rapidly near the border of New South Wales and Victoria to reach the ocean near Orbost. Its lower reaches have a considerable system of alluvial flats which do not need irrigation, but the country surrounding them is too poor and too uneven to be worthy of intensive development. From the agricultural point of view it is therefore preferable that the water should be diverted across the ranges towards the dry inland.

The use of water for power generation was neglected in the earlier days; but with increasing industrialization the need for this development became clear. Tasmania showed the way with its extensive system developed during the 'twenties. The difficulty of using water both for irrigation and electric generation lies in the seasonal nature of the requirement for the former, which is in contrast to the continuous use desirable in electric power systems. Clearly, it is almost essential that a dual-purpose project should be linked to a grid system of distribution. Such systems are evolving in parts of New South Wales and Victoria.

Many schemes have been put forward for the utilization of the Snowy waters. It became clear that, as two States and the Commonwealth were involved, no action could be taken without either mutual agreement or a most expensive legal argument. Agreement was reached in February 1949 on the basis of a report* submitted by Commonwealth and State officers.

The proposals contained in that report are for the interconnexion of the headwaters of the four main river systems (the Murray, Murrumbidgee, Tumut and Snowy systems) with the view of using them to the best advantage for irrigation at the lower reaches of the Murray and Murrumbidgee, but with inter-

* Commonwealth of Australia: Proposals to Divert the Snowy River. Report by Commonwealth and State officers. Nov. 1948. change of flow in the upper reaches for generation of electricity under the most favourable conditions. 'The Murray and Murrumbidgee themselves do not fall rapidly enough for this purpose; but the Tumut, Tooma (a tributary of the Murray) and part of the Snowy have sufficient gradient to provide satisfactory conditions for power generation.

There are several possible alternatives, and the final decision was reached after considering the relative importance of distribution of waters for irrigation, magnitude of power production, and the overall economics of both. The decision involves primarily the diversion of a large proportion of the Snowy waters indirectly to the Murrumbidgee. It has yet to be decided, after more detailed investigation, whether the remainder should be diverted to the Murray or the Murrumbidgee.

The details of the proposals may be examined in relation to the map of the area shown in Fig. 1. The main areas chosen for power production are: $(a)$ the upper reaches of the Snowy; (b) the Tumut valley; and (c) the area between the Snowy and the Murray. The flow of the Tumut River will be supplemented by the headwaters of the Tooma and of the Eucumbene branch of the Snowy, and lower down by waters of the upper Murrumbidgee. In the agreed part of the scheme the diversion from the Snowy to the Murray will be increased by a total amount equal to that lost by the Snowy. The remaining waters of the Snowy will be diverted either to the Murrumbidgee at Billilingera (the Snowy-MurrumbidgeeMurray-Tumut scheme), or to the Murray by the same route as the replacement diversion (the SnowyMurray-Tumut scheme). Power generation in the Tumut system will be supplemented by the Yarrangobilly River, and in the Snowy-Murray system by the Geehi River and Bogong Creek.

A flow diagram (Fig. 2) shows the effect of the diversions on the major rivers, for the Snowy-

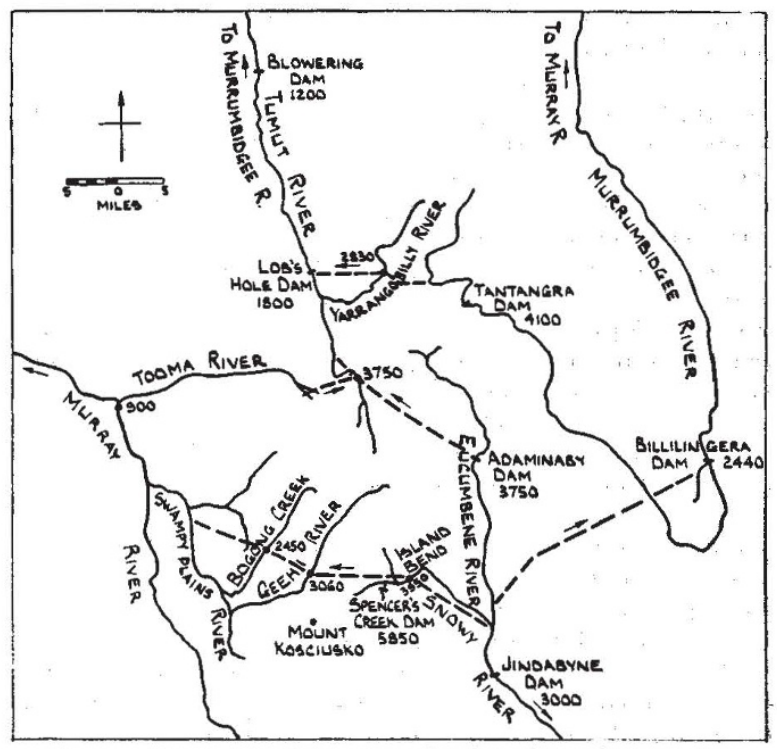

Fig. 1. Snowy Mountains area showing sites of major dams and diversions proposed (canals omitted). Figures are approximate 


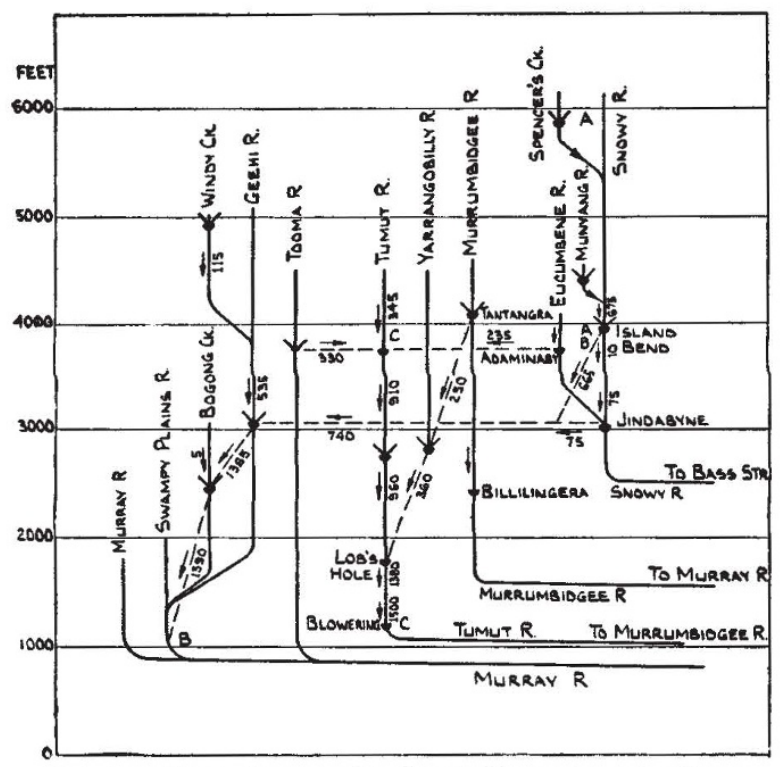

Fig. 2. Flow diagram for Snowy-Murray-Tumut scheme. Figures represent average flow in thousands of acre feet per annum.

Dams and collection points $\dot{\prime}$; racelines $\downarrow$; diversion tunnels Dams and collection points ; racelines $\$$; diversion tunnels Murray ; $C C$, Tumut

Murray-Tumut scheme. In the alternative scheme, the annual flow in the Snowy-Murray diversion tunnel would be reduced by 410,000 acre feet, a similar amount being diverted from Jindabyne Dam, on the Snowy, to Billilingera Dam, on the Murrumbidgee.

The total average power potential may be determined from the average flow at each dam or pond and its height above the point where the river ceases to fall rapidly. In the former scheme, the power potential in each of the three generating systems is thus approximately as follows: (a) Upper Snowy: $50,000 \mathrm{~kW}$. (b) Snowy-Murray diversion (Snowy R., Geehi R., and Bogong Creek): 430,000 kW. (c) Tumut (Eucumbene, Tooma, Tumut and Yarrangobilly Rivers): $410,000 \mathrm{~kW}$. The three systems have therefore a continuous power potential of $890,000 \mathrm{~kW}$. In the alternative scheme, the diversion of 410,000 acre feet per annum to the Murrumbidgee would cause a loss of about $60,000 \mathrm{~kW}$., but would have certain compensating advantages.

Having in mind the load factors at which the various power stations will operate when interconnected with existing and future generating stations in New South Wales, Victoria and the Federal Capital Territory, the proposals involve the installation of generating plant of $1,720,000 \mathrm{~kW}$. capacity in the case of the Snowy-Murray-Tumut scheme, or $1,565,000 \mathrm{~kW}$. in the alternative scheme.

The above analysis is based on data provided through the courtesy of the chairman of the Snowy River Committee, Mr. L. F. Loder, and used by the Committee in formulating its 1948 report. The whole area is relatively undeveloped, and it is accepted that the figures adopted are liable to modification when a more detailed survey has been made.

The magnitude of the scheme is indicated by the extent of the engineering works to be put in hand, involving the construction of more than eighty miles of tunnel and about five hundred miles of racelines. In addition, either of the alternative schemes will require the construction of seven major dams, some of them in country which has been hitherto regarded as fairly inaccessible. It is anticipated that the construction of the entire project will take some thirty years, but the benefits of the scheme will become progressively available during that time.

From the irrigation point of view, the water will be used to reinforce and extend the existing areas on the Murrumbidgee and Murray. These areas support very diverse forms of production, from dried fruits, citrus and canned fruits, and wine grapes, through irrigated pastures used for dairying or fat lambs, to rice and summer forages. In dry seasons considerable volumes are used to help crops of winter forage and grain. The allocation of water is through a system of 'rights' for which the landholder has to pay; extra supplies can also be purchased in some years. The right may be the equivalent of one foot of irrigation water over the whole holding, or may be one quarter to one tenth of a foot, depending on the nature and situation of the land. The landholder has to plan his type of production according to the size of his holding and his water-right, as various crops require various amounts; rice needs six feet, and winter forages perhaps only six or eight inches of water.

Soil problems are frequent in these areas, as the experiences of the last half-century have shown. Nowadays it is generally accepted that a more or less intensive soil survey is essential before any irrigation scheme is planned. Although some soil problems of irrigated land have not yet been solved, there is sufficient background of scientific knowledge available to ensure their satisfactory solution.

Sociologically, the more intensive the use of water, the closer will be the settlement of the land, and the larger the local units of population which can be established. Given effective leadership, such units can be more readily provided with the basic amenities which have not always been characteristic of rural areas. On the other hand, the forms of produce which lead to closest settlement, such as dried, canned and fresh fruits, and wine, are already avail. able far in excess of Australian requirements, while the future of dairy products is uncertain. It there. fore seems desirable that the water should be used to stimulate meat production and the growth of forages as reserves against the droughts which periodically afflict large areas. In this connexion it would be possible to irrigate localized areas in regions with an average rainfall of as low as $9 \mathrm{in}$. and a high degree of variability. However, this would mean passing the water down long stretches of river, with corresponding increases in the percentage lost through seepage and evaporation. The allocation of the water will thus become a very complicated problem, in the solution of which local interests must give place to the overall needs of the community.

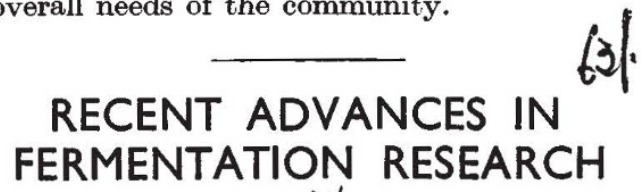

SYMPOSIUM/on 'ldkecent Advances in the Fermentatifo-Indue tries" was arranged by the Scottish Sec pos of the Foyal|Institute of Chemistry as a part of IIgeneral progpano of scientific courses, eorferen bs $^{\circ}$ and symposia And held at the University of St. Andrews during tuly 23-30. At a previous symposium in 1947, also held at St. Andrews, the 